Reports of the Progress of Applied Chemistry Vol. 21, 1936. Pp. 875. (London : Society of Chemical Industry, 1937.)

This volume appears so punctually year by year soon after the end of the period surveyed, and is so consistently full of well-digested reports, that every English-reading chemist must now be fully aware of its value; indeed, with many its appearance is reckoned an event. One reason for the welcome which always attends its arrival is evident; for after twelve months' struggle to keep one's head above the flood of chemical literature in which one is even mildly interested, a raft on which one may float awhile and contemplate the scenery is not to be despised. These surveys of progress in the several branches of technological chemistry appeal also to those who, having sufficient chemistry to follow their purport, are however not engaged in the work they describe, and perhaps would not regard themselves as chemists at all.

Among the new contributors are Mr. M. B. Donald (general, plant, and machinery), Dr. J. Grant (pulp and paper), and Dr. J. A. Sugden (refractories, ceramics, and cements), while Prof. W. E. S. Tüner (glass) and Dr. D. F. Twiss (rubber) are old friends who have returned. This year the biennial report on explosives is included. There are 26 sections in all, with general name and subject indexes, and of course the information presented is lavishly documented, references being given both to original sources and to abstracts. It would probably be fair to describe the Report as a whole as "better than ever"; which means that it reflects steady progress both in technical achievement and in presentation.

A. A. E.

Polychromatic Plates for Color Sense Examination By Dr. E. B. Rabkin. Pp. $40+x x$ plates. (Kharkov : State Medical Publishing Board, 1936.) 30 roubles. THIs series of tests for colour defect issues from the laboratory for colour vision of the Hirshman Memorial Ukrainian Central Ophthalmic Institute, of which Dr. Rabkin is the director. The tests are composed of coloured figures on coloured backgrounds, such as are found in the Stilling and the Ishihara tests. A number of the plates contain also 'hidden' figures, which are visible only to the dichromate. Triangles, circles and squares appear on some plates instead of figures, and so can be used for testing children and illiterates. A diagnosis can be made from the tables of dichromasy in general, and of protanopia, deuteranopia, and tritanopia in particular. The author claims, too, from the tests that "the simpler forms of anomalous trichromasy" can also be detected. Plates are added to detect simulation.

The series itself has been tested out in the Experimental Ophthalmic Clinic of the Institute of Experimental Medicine at Kharkov, and has proved successful. It seems, if one can judge from a preliminary survey, to give satisfactory results, and can be recommended. The book contains detailed and clear instructions in both Russian and English, although the English translation contains some curious phrases and sentences, and the spelling is not always of the best.
Organic Syntheses:

an Annual Publication of Satisfactory Methods for the Preparation of Organic Chemicals. L. F. Fieser, Editor-in-Chief. Vol. 17. (New York: John Wiley and Sons, Inc.; London: Chapman and Hall, Ltd., 1937.) 8s. 6d, net.

Produced on the plan now familiar to organic chemists and biochemists, the latest addition to this series contains details of thirty preparations. Among the open-chain substances are $\gamma$-aminobutyric acid, made by a modification of Gabriel's method; $\varepsilon$ aminocaproic acid, prepared from 2-ketohexamethylenimine; and 1,3-butadiene. It is stated that between $25 \mathrm{gm}$. and $30 \mathrm{gm}$. per hour of crude butadiene may be produced by passing the vapour of cyclohexene over a cracking element, in an ingenious apparatus which is here fully described with the aid of a diagram.

Of interest in carbohydrate chemistry is the account of the acetolysis of cotton, and of the hydrolysis of the resulting $\alpha$-cellobiose octa-acetate according to Zemplén's method. Biochemists will also welcome the details given for the hydrogenation of cholesterol to dihydrocholesterol ( $\beta$-cholestanol) and the oxidation of this to cholestanone. Under the heading of 2-carbethoxycyclopentanone (prepared from ethyl adipate) may be found a description of the useful Hershberg stirrer for pasty mixtures. Finally, the stereochemist is catered for in the precise directions given for the synthesis and complete optical resolution of that useful stereochemical agent, $\alpha$-phenylethylamine.

J. R.

\section{Mechanistic Biology and Animal Behaviour}

By Theodore H. Savory. Pp. xv +182 . (London : Watts and Co., 1936.) 7s. 6d. net.

Mr. Savory's book gives an eminently lucid and readable description of tropistic behaviour in some invertebrate organisms. The book, however, is largely devoted to an unconvincing exposition of certain well-worn theoretical issues. Mr. Savory defines his aim as the purely objective description of behaviour, which for the purposes of deterministic analysis he regards as the "visible response of an animal to some kind of stimulation which originates most frequently from a disturbance of its environment". He strays, however, from the logical demands of his definition, which is generally accepted by scientific students of behaviour, when he leaves the field of straightforward description. Thus, when he departs from the world of invertebrate organisms with which he is familiar, and discusses mammalian forms such as dogs, he accepts a priori concepts such as 'mind' and 'intelligent' as opposed to 'sub-intelligent' behaviour, and fails to realize that to the student of behaviour these concepts are somewhat empty. It is clearly illogical for the experimental investigator to ask whether spiders that lurk under stones have mind and self-awareness, and then to answer 'no' merely because the particular tropisms which drive spiders under stones have been defined.

The book closes with an uncritical statement about the influence of acquired habits on the course of arachnid evolution. 